\title{
PERCEPÇÕES DOS PROFESSORES DE MATEMÁTICA SOBRE A IMPORTÂNCIA DA LINGUA PORTUGUESA NO ENSINO-APRENDIZAGEM DA MATEMÁTICA
}

\author{
Irany Aparecida Ferreira da Cunha Barboza ${ }^{1}$ \\ (D) https://orcid.org/0000-0002-0409-8696 \\ Kilwangy Kya Kapitango-a-Samba ${ }^{2}$ \\ (D) https://orcid.org/0000-0002-9074-1587
}

Resumo: 0 presente artigo é consequente de uma pesquisa desenvolvida durante o curso de Mestrado em Ensino de Ciências e Matemática, na Universidade do Estado de Mato Grosso. Nosso objetivo foi analisar a contribuição do conhecimento da Língua Portuguesa no processo de ensino-aprendizagem da Matemática, a partir das percepções dos professores que ensinam Matemática nas Escolas da rede estadual, situadas na cidade de Araputanga, Mato Grosso, Brasil. Procuramos responder ao seguinte problema de pesquisa: quais as contribuições do conhecimento do padrão linguístico (língua portuguesa) no ensino-aprendizagem da Matemática, a partir das percepções dos professores de matemática? 0 método foi pesquisa de campo com entrevista semiestruturada para coleta de dados e, para o tratamento, a análise de conteúdo por categorização (Bardin, 2016). A amostra dos participantes foi de 10 professores licenciados em Matemática, num universo de 15 professores. Os resultados indicam que, nas percepções dos professores, o conhecimento do padrão da língua portuguesa é de fundamental relevância para o ensino-aprendizagem da Matemática, pois, permite: explicação e expressão acessível dos enunciados matemáticos; facilidade para compreensão e interpretação; conhecimento das regras gramaticais; flexibilidade no discurso; facilidade na escrita e; habilidade na comunicação.

Palavras-chaves: língua materna; formação inicial do professor; ensino de matemática.

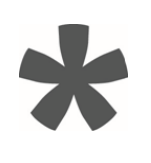

${ }^{1}$ Mestra em Ensino de Ciências e Matemática (PPGECM) Educação. Professora Governo do Estado do Mato Grosso: Araputanga, MT - Mato Grosso, BR. Escola Estadual Nossa Senhora de Fátima. E-mail: iranyferreira2582@gmail.com

2 Doutor em Educação: Ensino de Ciências e Matemática pela Universidade de São Paulo USP. Professor Adjunto de Metodologia Científica na Graduação e de Ciência da Aprendizagem na Pós-Graduação (UNEMAT) - Campus da Barra do Bugres, Mato Grosso, Brasil. E-mail: kapitango.samba@gmail.com 


\section{MATHEMATICS TEACHERS' PERCEPTIONS ABOUT THE IMPORTANCE OF PORTUGUESE LANGUAGE IN THE TEACHING-LEARNING OF MATHEMATICS}

Abstract: The present article is the result of a research developed during the course of a Master's degree in Science and Mathematics Teaching at the State University of Mato Grosso. Our objective was to analyze the contribution of the knowledge of the Portuguese Language in the teaching-learning process of Mathematics, based on the perceptions of teachers who teach Mathematics in state schools, located in the city of Araputanga, Mato Grosso, Brazil. We tried to answer the following research problem: what are the contributions of the knowledge of the linguistic standard (Portuguese language) in the teaching-learning of Mathematics, from the perceptions of mathematics teachers? The method was field research with semi-structured interviews for data collection and, for treatment, content analysis by categorization (Bardin, 2016). The sample of participants was 10 licensed teachers in mathematics, in a universe of 15 teachers. The results indicate that, in the teachers' perceptions, the knowledge of the Portuguese language standard is of fundamental relevance for the teaching-learning of mathematics, because it allows: explanation and accessible expression of mathematical statements; ease of understanding and interpretation; knowledge of grammatical rules; flexibility in speech; ease of writing and; ability in communication.

Keywords: mother tongue; initial teacher education; mathematics teaching.

\section{PERCEPCIÓN DE LOS PROFESORES DE MATEMÁTICAS SOBRE LA IMPORTANCIA DE LA LENGUA PORTUGUESA EN LA ENSEÑANZA-APRENDIZAJE DE LAS MATEMÁTICAS}

Resumen: El presente artículo es consecuencia de una investigación desarrollada durante el curso de Maestría en Enseñanza de Ciencias y Matemáticas, en la Universidad Estatal de Mato Grosso. Nuestro objetivo fue analizar la contribución del conocimiento de la Lengua Portuguesa en el proceso de enseñanza-aprendizaje de la Matemática, a partir de las percepciones de los profesores que enseñan Matemática en las Escuelas de la red estatal, ubicadas en la ciudad de Araputanga, Mato Grosso, Brasil. Intentamos responder al siguiente problema de investigación: ¿cuáles son las aportaciones del conocimiento de la norma lingüística (lengua portuguesa) en la enseñanza-aprendizaje de las matemáticas, desde las percepciones de los profesores de matemáticas? El método fue la investigación de campo con entrevistas semiestructuradas para la recogida de datos y, para el tratamiento, el análisis de contenido por categorización (Bardin, 2016). La muestra de participantes fue de 10 profesores licenciados en Matemáticas, en un universo de 15 profesores. Los resultados indican que, en la percepción de los profesores, el conocimiento de la norma de la lengua portuguesa es de fundamental relevancia para la enseñanza-aprendizaje de las Matemáticas, porque permite: la explicación y expresión accesible de los enunciados matemáticos; la facilidad de comprensión e interpretación; el conocimiento de las reglas gramaticales; la flexibilidad en el habla; la facilidad en la escritura y; la habilidad en la comunicación.

Palabras clave: lengua materna; formación inicial del profesorado; enseñanza de las matemáticas. 


\section{Introdução}

O desempenho dos estudantes nas avaliações externas ou internas tem sido ineficiente para o esperado no processo de ensino-aprendizagem da Matemática, esse é um consenso decorrente da mensuração da proficiência neste componente curricular. Apresentamos aqui resultados da pesquisa que visou analisar a contribuição do conhecimento do padrão da Língua Portuguesa ou língua materna ${ }^{3}$ no processo de ensino-aprendizagem da Matemática, a partir das percepções dos professores que ensinam Matemática nas Escolas estaduais, situadas na cidade de Araputanga, Mato Grosso, Brasil. Procuramos responder ao seguinte problema de pesquisa: quais as contribuições do conhecimento do padrão linguístico da Língua Portuguesa no ensino-aprendizagem da Matemática, a partir das percepções dos professores de matemática?

A amostra da pesquisa foi de 10 professores, que compõem o total de docentes que lecionam nas três escolas estaduais urbanas, nos anos finais do ensino fundamental e ensino médio, num universo de 15 docentes licenciados em e lecionam matemática ( 3 escolas urbanas e 3 rurais). 0 critério de seleção, entre zona rural e urbana, foi a amostragem intencional considerando a variável logística-distância. 0 lócus foi a cidade de Araputanga-MT.

Adoção da abordagem qualitativa ${ }^{4}$ justificou-se pelo fato de que ela permite compreender e aprofundar os fenômenos a partir do ponto de vista dos participantes da pesquisa. Elegemos a pesquisa de campo, com entrevista semiestruturada - que permite ao pesquisador obter informações que estão além do roteiro da entrevista (HERNÁNDEZ SAMPIERI, 2013) e da Análise de Conteúdo ${ }^{5}$ qualitativa por categorização (BARDIN, 2016). No processo de categorização, o critério pode ser o meio semântico, sintático, lexical ou ainda expressivo. Ao analisarmos as narrativas dos professores, seguimos uma análise indutiva, levando em consideração esses critérios para criarmos diferentes categorias de análise.

A pesquisa empírica foi antecedida de: a) - Análise documental dos Projetos Pedagógicos de Cursos (PPC) de Licenciaturas em Matemática de quatro Instituições de Ensino Superior situadas no Estado de Mato Grosso ${ }^{6}$. Nos PPC analisamos as ementas de Língua Portuguesa ou de disciplinas afins; b) - Análise bibliográfica das

\footnotetext{
3 Daqui em diante, utilizamos língua materna e Língua Portuguesa como sinônimos.

4 Ela, é selecionada quando buscamos compreender a perspectiva dos participantes (indivíduos ou grupos, pequenos de pessoas que serão pesquisados) sobre os fenômenos que os rodeiam, aprofundar em suas experiências, pontos de vista, opiniões e significados, isto é, a forma como os participantes percebem subjetivamente sua realidade. (HERNÁNDEZ SAMPIERI, 2013, p. 376).

5 É “[...] uma operação de classificação de elementos constitutivos de um conjunto por diferenciação e, em seguida, por reagrupamento segundo o gênero (analogia), com os critérios previamente definidos. As categorias são rubricas ou classes, as quais reúnem um grupo de elementos (unidade de registro ou análise de conteúdo) sob um título genérico, agrupamento esse efetuado em razão das características comuns destes elementos." (BARDIN, 2016, p. 147).

6 Instituto Federal de Ciências e Tecnologia de Mato Grosso (IFMT), Universidade de Cuiabá (UniC), Universidade do Estado de Mato Grosso (UNEMAT) e Universidade Federal de Mato Grosso (UFMT).
} 
produções científicas que tratam das contribuições da Língua Portuguesa no ensinoaprendizagem da Matemática, a partir de três bases de dados: Google Acadêmico; Base de Teses e Dissertações da Coordenação de Aperfeiçoamento de Pessoal de Nível Superior (CAPES) e Scielo. Alguns autores ${ }^{7}$ têm se debruçado sobre a relação Língua Portuguesa e Matemática e suas pesquisas apresentam procedimentos metodológicos e contextos diferenciados, com um público específico, cada trabalho traz seus resultados conforme as particularidades de cada situação estudada. Em todos os trabalhos fica evidente o consenso da relevância do domínio das habilidades do padrão linguístico, para desempenho no ensino-aprendizagem da Matemática.

\section{RELEVÂNCIA DA LÍNGUA PORTUGUESA PARA O ENSINO-APRENDIZAGEM DA MATEMÁTICA}

A formação inicial é essencial para a profissionalização, a constituição da identidade e o desempenho profissional docente, desde que forneça uma base sólida de conhecimentos e habilidades para atuação autônoma no complexo trabalho docente. Assim, ela precisa ser pensada de modo a oferecer as bases para que o profissional possa construir as capacidades e habilidades essenciais, para fluência criativa e crítica na futura prática docente. 0 futuro docente necessitará de uma gama de conhecimentos e saberes sólidos em ciências, didática, metodologia, sociocultura, neuropsicopedagogia, gestão, padrão linguístico pátrio e relações sociais, entre outros, de modo a ser capaz de assumir a tarefa educativa e desempenhá-la em sua complexidade 8 .

Nesse sentido, as instituições de ensino desempenham um papel formativo decisivo, não apenas transmitir conhecimento específico, mas desenvolver capacidades para diversas exigências da profissão docente e da sociedade. Assim, "Essa formação que confere o conhecimento profissional básico, deve permitir trabalhar em uma educação do futuro, o que torna necessário repensar tanto os conteúdos quanto a metodologia em que estes são transmitidos." (IMBERNÓN, 2011, p. 65). Portanto, mudança estruturante.

Foram identificados nove cursos de Licenciatura em Matemática e três disciplinas de, respectivamente: IFMT dois cursos; UFMT quatro cursos; UniC nenhum curso e UNEMAT três cursos e três disciplinas de Produção de Texto e Leitura, apenas nesta última instituição. As três disciplinas ofertadas pela UNEMAT possuem uma carga horária mínima para aprendizagem da estrutura, organização e funcionamento

\footnotetext{
7 Considerando o caráter do trabalho e à título de exemplificação, citamos os seguintes autores: Bittencourt (2008), Campos e Barcelos (2015), Coura (2006), Freitas (2015), Marques (2008), Pinheiro e Alves (2015), Silva (2013), Silveira e Ripardo (2016), entre outros.

80 que nos permite concordar com Imbernón ao afirmar que "É preciso estabelecer um preparo que proporcione um conhecimento válido e gere uma atitude interativa e dialética, que leve a valorizar a necessidade de uma atualização permanente em função das mudanças que se produzem: a criar estratégias e métodos de intervenção, cooperação, análise, reflexão; a construir um estilo rigoroso e investigativo. Aprender também a conviver com suas próprias limitações e com as frustações e condicionantes produzidos pelo entorno, já que a função docente se move em contextos sociais que, cada vez mais, refletem forças em conflito." (IMBERNÓN, 2011, p. 63).
} 
da Língua Portuguesa e habilidades de redação acadêmica, conforme ilustrações seguintes:

\section{Ementas de Produção de Texto e Leitura da UNEMAT.}

\begin{tabular}{|l|}
\hline Identificação da Disciplina - Campus da Barra do Bugres (PPC, 2009) \\
\hline Disciplina: Produção de Texto e Leitura. Pré-Requisitos: não possui. Carga Horária: 60 Horas \\
\hline Ementa \\
\hline Leitura, interpretação e elaboração de textos acadêmicos (resenha, resumos, artigos, ensaios e \\
relatrios). Coesão, a coerência e a argumentação. \\
\hline Identificação da Disciplina - Campus de Cáceres (PPC, 2018) \\
\hline Disciplina: Produção de Texto e Leitura - 60h Pré-requisito: não possui \\
\hline Ementa \\
\hline e relatórios). Coesão, a coerência e a argumentação \\
\hline Identificação da Disciplina - Campus de Sinop (PPC, 2013) \\
\hline Disciplina: Produção de Texto e Leitura, Carga horária: 60h. Pré-requisito: não possui \\
\hline Ementa \\
\hline Leitura, interpretação e elaboração de textos acadêmicos (resenhas, resumos, artigos, ensaios \\
e relatórios). Coesão, a coerência e a argumentação.
\end{tabular}

Fonte: Adaptado da Unemat $(2009,2018,2013)$.

Os componentes curriculares apresentam a mesma ementa focada em habilidades de comunicação oral e escrita: leitura, interpretação e redação de textos acadêmicos, com coesão, coerência e argumentação. Essa tendência corrobora com a perspectiva de que a produção de textos é o ponto de partida da aprendizagem do padrão da língua, pois, é "no texto que a língua se revela em sua totalidade" (GERALDI, 1993, p. 135), que permitiria o desenvolvimento das habilidades linguísticas ${ }^{9}$ de comunicação em diversos contextos, sobretudo, no contexto profissional didáticoacadêmico. A produção textual é vista, então, como uma forma de atividade que valoriza o papel do sujeito autoral histórico na produção científica e, por meio de enunciados escritos, o indivíduo pode interagir com os leitores de diferentes momentos históricos.

\footnotetext{
9 Segundo o Glosário Ceale (ISBN: 978-85-8007-079-8): “Escutar, falar, ler e escrever são quatro habilidades básicas que nos permitem agir socialmente no uso da língua. Ou seja, essas são as habilidades linguísticas que as pessoas desenvolvem ao se relacionarem e comunicarem umas com as outras." Disponível em: <http://www.ceale.fae.ufmg.br/app/webroot/glossarioceale/verbetes/habilidades-linguisticas>. Acesso em; 31 mai. 2020. Portanto, as quatro habilidades básicas podemos acrescentar outras quatro habilidades avançadas que podem incluir: análise, interpretação, compreensão e tradução, necessárias na formação profissional docente.
} 
A ausência de componente curricular da área de língua portuguesa nos cursos das demais instituições de ensino torna-se preocupante. Parece que essa ausência se deve ao senso comum dominante no ensino superior de que não é necessário inclusão de Língua Portuguesa no currículo, já todos falamos essa língua. No entanto, essa concepção é equivocada, pois todos as atividades dos componentes curriculares são realizadas em língua pátria (Português). Portanto, o conhecimento aprofundado da estrutura e funcionalidade do padrão linguístico: morfossintático, semântico e léxico do português formal é fundamental para o melhor desempenho cognitivo, por exemplo, para mitigar problemas de falta de coerência, coesão e concordância na formulação de enunciados matemáticos e favorecer a consistente análise, interpretação, compreensão e argumentação intelectual.

As ementas estão reduzidas, pois, não identificamos elementos de aprendizagem de análise morfológica, sintática e semântica e outros conteúdos essenciais para a proficiência linguística. Esse fato, gera um déficit de aprendizagem e domínio do padrão linguístico nos futuros docentes e favorece atos de copiar problemas matemáticos de livros didáticos ou de vestibulares digitalizados e disponíveis pela internet ${ }^{10}$. Na pesquisa empírica, verificamos que dois docentes não se formaram no Estado de Mato Grosso e afirmam não terem tido nenhuma disciplina da área de Língua Portuguesa. E, os oito são licenciados pela UNEMAT (Cáceres), afirmaram terem estudado "Produção de Texto e Leitura (PTL)" durante a licenciatura.

Questionados se o estudo da língua realizado durante a licenciatura trouxe contribuições suficientes para a construção do conhecimento acadêmico do padrão linguístico para Ensino de Matemática, as afirmações foram variadas, mas trazem percepções sobre os estudos realizados durante a licenciatura. Três docentes ${ }^{11}$ afirmaram, em síntese, que o estudo realizado não contribuiu o suficiente para desenvolvimento de hablidades linguísticas que lhes permitisse o ensino, a produção, interpretação e leitura de textos matemáticos sem percalços do padrão linguísticos, pois “[...] o que vimos foi gramática, não foi a questão da produção mesmo, que viesse contribuir para o ensino da matemática."(P1). Essa pode ser uma forma reducionista de ensino da língua focado apenas no ordenamento gramatical sem relação com o contexto acadêmico em que ela se aplica. Excetuando os cursos de letras, geralmente,

\footnotetext{
10 Através da Word Wide Web (rede mundial de computadores).

11 Vide: P1: “Nós tivemos poucas aulas de produção de texto na faculdade, e os temas abordados lá não contribuíram tanto. Nós vimos, nós vimos muito.... pouco né, e o que vimos foi gramática, não foi a questão da produção mesmo, que viesse contribuir para o ensino da matemática." (Entrevista concedida em 26 abr. 2019). P3: "Muito pouco. No estudo acadêmico poderia ser melhor trabalhado produção, interpretação, leitura, porém, a gente tem um semestre, dois semestres, no máximo, e eu não vejo tempo suficiente, já que você vai trabalhar isso em sala de aula, com alunos do fundamental e médio." (Entrevista concedida em 26 abr. 2019). P10: "Infelizmente não, porque um semestre é ...não é suficiente "pra gente" trabalhar a disciplina de Língua Portuguesa dentro, "né" da disciplina de Matemática. De forma nenhuma, porque assim, a LP é muito ampla, então o conhecimento que eu tenho de LP, é o conhecimento mesmo do Ensino Médio, e assim, as leituras "que a gente" vem fazendo a longo dos anos. Mas, dentro da minha graduação eu não sai preparada de forma nenhuma para trabalhar alguns conteúdos da LP que é exigido, na verdade é necessário, para trabalhar dentro da Matemática também." (Entrevista concedida em 26 abr. 2019).
} 
a disciplina predominante nos demais cursos é da Produção de Texto e Leitura, que também, "No estudo acadêmico poderia ser melhor trabalhado produção, interpretação, leitura [...]." (P3), e, quanto isto não ocorre, "então o conhecimento que eu tenho de LP, é o conhecimento mesmo do Ensino Médio, e assim, as leituras 'que a gente' vem fazendo a longo dos anos. Mas, dentro da minha graduação eu não sai preparada de forma nenhuma para trabalhar alguns conteúdos da LP que é exigido, na verdade é necessário, para trabalhar dentro da Matemática também." (P10) ${ }^{12}$

A produção de texto deveria ser compreendida de forma mais profunda aos textos de enunciados matemáticos e não restringida aos gêneros textuais, para que os conhecimentos da língua padrão e suas habilidades fossem desenvolvidas dentro das capacidades profissionais e científicas. Um enunciado matemático é um texto que requer toda qualidade e coerência científicas necessárias para ser produzido, analisado, interpretado, compreendido e explicado ao e por estudantes.

Os outros cinco professores ${ }^{13}$ afirmaram que a contribuição foi ínfima ou parcial e consistiu na aprendizagem da escrita de textos/artigos e um pouco de gramática, porém, um estudo mais aprofundado favoreceria tanto estudantes quanto docentes na compreensão de enunciados matemáticos, pois "Noventa por cento da Matemática é escrita e o outro restante é cálculo. Então é... de forma direta, essa forma de produção contribui para nossa formação." (P4). Percebe-se que há um eixo comum entre os participantes tanto sobre a contribuição razoável para produção de trabalhos quanto sobre a insuficiência da aprendizagem das habilidades de produção, leitura, análise, interpretação e compreensão de textos científicos matemáticos, afinal “[...] muitos exercícios trabalhados com enunciados que, muitas vezes, os alunos não consegue [sic] a interpretação, até alguns colegas de profissão, às vezes, se atrapalham com isso." (P2).

\footnotetext{
${ }^{12}$ A experiência relatada não é isolada. 0 abandono dos estudos do padrão linguístico aplicado aos diversos campos de formação universitário tem sido predominante, o que torna o ensino superior um espaço para produção de um certo tipo de analfabetismo. Os estudantes excluídos de estudos avançados do padrão da língua e sua aplicação às suas áreas profissionais durante a graduação, o mestrado e doutorado possuem, formalmente, conhecimentos linguísticos do Ensino Médio. Caberá a cada um a busca pessoal por desenvolvimento de suas habilidades linguísticas, entretanto, cabe à educação básica ou superior proporcioná-lo.

${ }^{13}$ Vide: P2: "O que... que..., o que trouxe favorece, às vezes, na compreensão nos estudos dos textos, porque algumas vezes, vem muitos exercícios trabalhados com enunciados que, muitas vezes, os alunos não consegue [sic] a interpretação, até alguns colegas de profissão, às vezes, se atrapalham com isso." (Entrevista concedida em 26 abr. 2019). P4: "Contribuiu para redigir textos, escrever, produzir trabalhos voltados para a escrita. Levando em consideração a necessidade de interpretação e escrita. Noventa por cento da Matemática é escrita e o outro restante é cálculo. Então é... de forma direta, essa forma de produção contribui para nossa formação." (Entrevista concedida em 26 abr. 2019). P5: "Essa matéria... veio contribuir, eu acho que na produção de textos, na época, de trabalhos científicos, que a gente fez, né, é... e artigos que a gente publicou em alguns sites." (Entrevista concedida em 26 abr. 2019). P7: "Bom, é trouxe um conhecimento bom, porém é... as vezes a gente se depara com situações que é preciso a gente conhecer um pouco mais, então, dependente de falar assim suficiente, talvez não porque a gente sempre "tá" buscando melhorar". (Entrevista concedida em 26 abr. 2019). P8: "Então, ajudou, mas só que ainda faltou, porque foi só produção de artigo científico, gramática bem pouco, ou seja, faltou mais, foi só um semestre." (Entrevista concedida em 26 abr. 2019).
} 
No geral, os estudos de Produção de Texto e Leitura estão voltados aos gêneros textuais e um pouco à escrita de trabalhos científicos acadêmicos. Os estudos linguísticos não poderiam ser restringidos à produção de trabalhos de conclusão de cursos, mas ampliados aos textos matemáticos, em especial, os didáticos, que têm apresentado uma complexidade no ensino-aprendizagem da matemática.

Quanto aos dois docentes que não estudaram algum componente curricular linguístico descreveram uma realidade de ausência total, retrataram um currículo fechado ${ }^{14}$. É fato constatável nos relatos que os conteúdos estudados, em um semestre, não contribuíram o suficiente para aquisição de conhecimentos essenciais e domínio das habilidades linguísticas necessárias para a prática docente. 0 déficit de aprendizagem do padrão linguístico gerado repercutir-se-á na prática didática e na aprendizagem discente. Pois, é preciso dominar a complexidade do padrão linguístico (ex.: léxico, morfossintaxe, semântica) dos textos matemáticos que determina a qualidade e o grau de ensino-aprendizagem matemática. Eles estão cientes de que é por meio da aprendizagem do padrão linguístico que se realizam as leituras e as estratégias de selecionar, antecipar, localizar, inferir, analisar, interpretar, entender e avaliar, ensinar e aprender a matemática ${ }^{15}$. Pois, considerando que todas as disciplinas são ensinadas em língua nacional, disso resulta que "Se eu não sei português, dificilmente eu vou conseguir interpretar os meus problemas, onde ele

14 Vide: P9: "Nenhuma delas, naquela época, praticamente, era Matemática pura, então a gente tinha Matemática pura, Matemática aplicada, estatística, tudo na área de Matemática." (Entrevista concedida em 26 abr. 2019). P6: "Nenhuma das opções. Porque quando fiz a graduação nós não estudamos Língua Portuguesa, era somente cálculos, Matemática pura." (Entrevista concedida em 26 abr. 2019).

15 Vide: P1: "Com certeza, desde uma linguagem de fácil acesso aos alunos na hora da explicação, uma linguagem nos enunciados das atividades, tudo isso contribui." (Entrevista concedida em 07 jun. 2019). P2: "Tudo. Se eu não sei português, dificilmente eu vou conseguir interpretar os meus problemas, onde ele necessita-se pensar. Se eu não sei ler, eu não vou conseguir interpretar e absorver o que o problema me traz." (Entrevista concedida em 07 jun. 2019). P3: "É, eu vejo de extrema importância, pois pra gente elaborar uma atividade, essa atividade tem que estar, ah, com as devidas concordâncias, até mesmo, porque se não tiver, nosso aluno não vai entender o que está sendo pedido. E questão de pontuação, virgula, tudo isso, para melhor compreensão do aluno." (Entrevista concedida em 07 jun. 2019). P4: "Para nós professores de Matemática, no caso eu, levo em consideração a flexibilidade de mudança é ... na fala, no planejamento da aula, eu posso planejar minha aula, e durante o planejamento, eu vou, eu vou criar uma ideologia para "mim" transpor os conceitos matemáticos, mas no momento que chego em sala de aula, pode ocorrer que a forma que eu vou apresentar o conteúdo seja muito complexo para o nível da turma. Então eu tenho que flexibilizar meu planejamento, apresentar numa linguagem mais fácil, sem perder a ideologia do contexto matemático, na forma que meu aluno tenha uma melhor compreensão." (Entrevista concedida em 07 jun. 2019). P5: "Então, é... essas contribuições hoje é ... eu acredito que vem na compreensão do que se, do que se diz no enunciado. Por exemplo, na resolução de cálculos, por exemplo você passa uma problemática, se o aluno não consegue entender, a... o que se pede, o que se diz, ele não consegue fazer uma associação com o cálculo, eles não conseguem desenvolver o cálculo." (Entrevista concedida em 07 jun. 2019). P6: "Na escrita né, no desenvolvimento das tarefas, no diálogo mais facilitado com, com os alunos, né "pra tá" ajudando-os na interpretação, na resolução dos exercícios." (Entrevista concedida em 07 jun. 2019). P7: "Bom, é conhecimento em português, ajuda tanto a interpretar as questões, mas também, não só na Matemática, mas em qualquer disciplina, ensina a interpretar, pontuação, ajuda a entender bem, porque o fato de 'tá' mal pontuado, atrapalha a intepretação, então tudo isso acarreta uma boa interpretação de um questionário matemático." (Entrevista concedida em 07 jun. 2019). P8: "No ato de falar, de comunicar, de explicar, trazer algumas situações problemas que possa contribuir para a aprendizagem do aluno, ela "tá" envolvida diretamente com a Matemática." (Entrevista concedida em 07 jun. 2019). 
necessita-se pensar. Se eu não sei ler, eu não vou conseguir interpretar e absorver o que o problema me traz." (P2).

A construção e explicação de uma situação-problema requer o conhecimento do padrão linguístico, pois, é nele que a matemática é comunicada, lida, interpretada e compreendida ${ }^{16}$, pois, "[...] pra gente elaborar uma atividade, essa atividade tem que estar, ah, com as devidas concordâncias, até mesmo, porque se não tiver, nosso aluno não vai entender o que está sendo pedido. E questão de pontuação, virgula, tudo isso, para melhor compreensão do aluno." (P3). Isto só é possível ao docente que domina o padrão linguístico. A referência à importância de tal estudo é feita em relação aos estudantes, para que eles possam interpretar e compreender os problemas matemáticos ${ }^{17}$. Mas, não pode ser restringida apenas aos estudantes saberem interpretar para compreenderem, aos docentes de matemática também se requer saberem escrever e elucidar as questões matemáticas. Um enunciado escrito incorretamente não garante interpretação coerente alguma. Ademais, o caminho que leva à compreensão da matemática depende do processo em que é ensinada e aprendida.

Assim, a formação docente inicial não é a única responsável pela construção do saber linguístico fundamental ao desempenho profissional, mas se apresenta como uma etapa indispensável para a profissionalização, o exercício da profissão e a promoção e mediação da aprendizagem matemática. Esta é expressa e ensinada em língua materna, então, não a estudar, significa não promover as habilidades linguísticas necessárias. É objetivo da formação inicial proporcionar a construção dos saberes docentes de maneira que estes permitam estabelecer relações entre os saberes científicos em processo de construção, na formação profissional ${ }^{18}$. Porém, embora necessária e urgente a reformulação da formação dos professores é um

16 Daí também o reconhecimento da relevância didática da aprendizagem eficaz do idioma padrão em todas as áreas de formação profissional.

17 Vide: “Olha, a Língua Portuguesa é muito importante, não só na área da Matemática, mas em todas as áreas, a grande verdade é o seguinte: hoje com os livros didáticos, com as pesquisas que nós podemos fazer com nossos alunos, depende muito da interpretação de texto, depende muito do aluno saber ler e escrever corretamente, então é... a Matemática não caminha sozinha, ela depende do português para que ela seja bem interpretada e bem realizada, até para os alunos saber que tipo de trabalho ou operação que ele vai fazer, se ele souber interpretar o texto, se ele souber interpretar o problema, se ele souber interpretar a matéria que está sendo dada." (P9). (Entrevista concedida em 07 jun. 2019). Ou ainda, "[...] a gente fala que fazer a demonstração do cálculo não é difícil, o que é mais difícil na Matemática é a compreensão, né, e a interpretação do enunciado, então, muitas vezes os alunos tem dificuldade em fazer essa compreensão. Então o que que acontece, eu tenho extrema dificuldade também de "tá" transmitindo isso para o aluno, pra "tá" passando isso para o aluno, porque eu não tenho uma preparação pra fazer isso, o professor de LP, ele estudou ele tem toda uma metodologia, pra "tá" explicando, como que o aluno interpreta, como que interpreta uma questão, ah, normalmente há alguma palavra de duplo sentido, e que normalmente nós da área de exatas não temos essa preparação." (P10) (Entrevista concedida em 07 jun. 2019).

18 Assim, concordamos que "É preciso derrubar o predomínio do ensino simbólico e promover um ensino mais direto, introduzindo na formação inicial uma metodologia que seja presidida pela pesquisa-ação como importante processo de aprendizagem da reflexão educativa, e que vincule constantemente teoria e prática. (IMBERNÓN, 2011, p. 67). 
desafio para as próprias universidades devido à complexidade das disputas políticas curriculares e aos fracassos em formar professores pesquisadores que saibam vincular teoria e prática. Para isso, é fundamental o conhecimento em diversas áreas e não só na área de formação específica ${ }^{19}$. Na sociedade em transformação, o conhecimento da língua materna é indispensável e primordial para a aprendizagem, pois ela está presente em todas as áreas, faz parte da comunicação e interação entre todos e tudo 20 .

Assim, construímos algumas categorias sobre as contribuições da Língua Portuguesa na prática docente em Matemática, com base nas percepções dos entrevistados, que permitem identificar sentido nos dados, analisá-los segundo a fala de cada participante e revelar suas percepções e aflições. Tais categorias são:

\begin{tabular}{|c|c|}
\hline \multicolumn{2}{|c|}{ Categorias sobre a contribuição da LP no Ensino de Matemática } \\
\hline $\begin{array}{l}\text { Sujeitos das } \\
\text { Verbalizações } \\
\text { (Entrevista concedida em } \\
07 \text { jun. 2019) }\end{array}$ & $\begin{array}{l}\text { Categorias } \\
\text { [LP contribui para] }\end{array}$ \\
\hline $\mathbf{P 1}{ }^{21}$ & $\begin{array}{l}\text { Explicação e expressão acessível dos enunciados } \\
\text { matemáticos }\end{array}$ \\
\hline P2, P7, P9 e P10 22 & Facilidade para compreensão e interpretação \\
\hline
\end{tabular}

19 Vale salientar aqui que "Os cursos de preparação para a formação inicial deveriam ter um papel decisivo na promoção de todos os aspectos da profissão docente, comprometendo-se com o contexto e a cultura em que esta se desenvolve. Devem ser instituições 'vivas', promotoras da mudança e da inovação. Os futuros professores também devem estar preparados para entender as transformações que vão surgindo nos diferentes campos e para ser receptivos e abertos a concepção pluralistas, capazes de adequar suas atuaç̧ões às necessidades dos alunos em cada época e contexto." (IMBERNÓN, 2011, p. 64).

${ }^{20}$ Consideração as traduções para os usuários da Língua Brasileira de Sinais (Libras) e Braille.

${ }^{21}$ P1: "Com certeza [traz contribuições], desde [proporcionar] uma linguagem de fácil acesso aos alunos na hora da explicação, uma linguagem nos enunciados das atividades... Tudo isso contribui."

22 P2: “Tudo. Se eu não sei português, dificilmente eu vou conseguir interpretar os meus problemas, onde ele necessita pensar. Se eu não sei ler, eu não vou conseguir interpretar e absorver o que o problema me traz." P7: "Bom, é conhecimento em português ajuda tanto a interpretar as questões, mas também não só na Matemática, mas em qualquer disciplina. Ensina a interpretar, pontuação, ajuda a entender bem, porque o fato de tá mal pontuado atrapalha a intepretação. Então, tudo isso acarreta uma boa interpretação de um questionário matemático." P9: “Olha, a Língua Portuguesa é muito importante não só na área da Matemática, mas em todas as áreas. A grande verdade é o seguinte: hoje com os livros didáticos, com as pesquisas que nós podemos fazer com nossos alunos, depende muito da interpretação de texto. [...] A Matemática não caminha sozinha, ela depende do Português para que ela seja bem interpretada e bem realizada. Até para os alunos saber que tipo de trabalho ou operação que ele vai fazer, se ele souber interpretar o texto, se ele souber interpretar o problema, se ele souber interpretar a matéria que está sendo dada..." P10: “Olha, a Matemática, em si, a gente fala que fazer a demonstração do cálculo não é difícil, o que é mais difícil na Matemática é a compreensão, né? e a interpretação do enunciado, então, muitas vezes, os alunos têm dificuldade em fazer essa compreensão. Então, o que que acontece? eu tenho extrema dificuldade também de tá transmitindo isso para o aluno, pra tá passando isso para o aluno, porque eu não tenho uma preparação pra fazer isso. 0 professor de LP, ele estudou, ele tem toda uma metodologia, pra tá explicando, como que o aluno interpreta, como 


\begin{tabular}{|l|l|}
\hline P3 $^{23}$ & Conhecimento das regras gramaticais \\
\hline P4 $^{24}$ & Flexibilidade no discurso \\
\hline P6 e P925 $^{25}$ & Facilidade na escrita \\
\hline P8 $^{26}$ & Habilidade de comunicação \\
\hline
\end{tabular}

Fonte: os autores (2019)

\section{$\mathrm{Na}$ categoria Explicação e Expressão Acessível dos Enunciados}

Matemáticos, extrai-se que o ato de ensinar e aprender está inserido no ato de se expressar de forma oral, escrita ou gestual, o que exige a presença de um emissor e de um receptor ligados por um canal de comunicação, para a transmissão de uma mensagem, em um contexto espaço-temporal e histórico-cultural. Nos ambientes que ocorre a interação professor-estudantes, as interações formativas que nela se estabelecem são mediadas pela linguagem. E, a linguagem em que a Matemática é expressa (ensinada e aprendida) é considerada híbrida ${ }^{27}$, ela é a união da linguagem verbal (escrita, oral) com a não-verbal (simbólica, pictórica ou icónica), o que lhe confere mais complexidade, dadas as suas dimensões do implícito e explicito. Essa característica permite afirmar que “[...] a Matemática possui uma linguagem específica, cujos termos nem sempre guardam relação direta com seu significado da língua materna28." (AZERÊDO; RÊGO, 2016, p. 159).

que interpreta uma questão. Ah, normalmente há alguma palavra de duplo sentido, e que normalmente nós, da área de exatas, não temos essa preparação."

${ }^{23}$ P3: “É, eu vejo de extrema importância, pois pra gente elaborar uma atividade, essas atividades têm que estar, ah, com as devidas concordâncias, até mesmo porque, se não tiver, nosso aluno não vai entender o que está sendo pedido. E questão de pontuação, vírgula, tudo isso, para a melhor compreensão do aluno."

${ }^{24}$ P4: "Para nós, professores de Matemática, no caso eu, levo em consideração a flexibilidade de mudança, é ... na fala, no planejamento da aula, eu posso planejar minha aula e, durante o planejamento, eu vou, eu vou criar uma ideologia para mim transpor os conceitos matemáticos, mas, no momento que chego em sala de aula, pode ocorrer que a forma que eu vou apresentar o conteúdo seja muito complexo para o nível da turma. Então, eu tenho que flexibilizar meu planejamento, apresentar numa linguagem mais fácil, sem perder a ideologia do contexto matemático, na forma que meu aluno tenha uma melhor compreensão."

25 P6: "Na escrita, né?, no desenvolvimento das tarefas, no diálogo mais facilitado com, com os alunos, né?, pra tá ajudando eles na interpretação, na resolução dos exercícios." P9: “[...] a Língua Portuguesa é muito importante, depende muito do aluno saber ler e escrever corretamente."

${ }^{26}$ P8: "No ato de falar, de comunicar, de explicar, trazer algumas situações-problemas que possa contribuir para a aprendizagem do aluno, ela [a LP] tá envolvida diretamente com a Matemática."

27 A matemática é considerada como possuidora de uma linguagem específica como um sistema simbólico próprio, cujos símbolos se relacionam segundo determinadas regras. Ela é considerada hibrida devido o resultado do cruzamento da linguagem simbólica (números e equações com letras) com a linguagem materna.

${ }^{28}$ Vide "Por exemplo: a palavra dividir, em Matemática, carrega conceitualmente o significado de uma operação que pressupõe o desmembramento de unidades em partes necessariamente iguais. 0 ato de 
Assim, a qualidade da atividade didática, da comunicação e do tipo de linguagem envolvida depende, em grande medida, da formação sólida e da forma como o professor organiza as situações de ensino-aprendizagem e o trabalho dos estudantes; de como os orienta, questiona, expõe, explica ou conjectura; de como os estudantes discutem entre si e como o professor interage com esses estudantes. Uma forma de exploração do uso da língua materna é abrir espaço à participação estudantil, com exposição de suas ideias e posicionamentos sobre diversas situações de ensino-aprendizagem da matemática, por exemplo, a "pergunta torna-se muito importante nesse contexto e desempenha um papel fundamental, pois poderá conduzir ao desenvolvimento de comunicações e interações específicas que promovam desenvolvimento." (NACARATO; MENGALI; PASSOS, 2017, p. 72). A linguagem oral ou escrita dos enunciados matemáticos deve ser acessível aos estudantes, para promoção de interesse e motivação, essenciais à estimulação cognitiva e da aprendizagem matemática.

$\mathrm{Na}$ Facilidade para Compreensão e Interpretação, as habilidades necessárias para a aprendizagem da Matemática incluem, entre outras, a interpretação dos enunciados matemáticos e o conhecimento da língua materna, para o desenvolvimento do raciocínio lógico ampliado. Os estudantes convivem com textos matemáticos diariamente, interpretarão enunciados durante toda a sua vida social e acadêmica e a realização de atividades de leitura está diretamente ligada à língua materna. Dessa forma, é inegável a importância da interpretação textual para a resolução de problemas matemáticos, na perspectiva de $\operatorname{Kleimanan}^{29}$ (2000, p. 13). Segundo a autora, o estudante precisa utilizar todo o seu conhecimento prévio, como o conhecimento linguístico, textual e de mundo, ele precisa ser proficiente em língua materna para conseguir interpretar as situações de leitura matemática, no caso. Visto que, a linguagem matemática é representação simbólica da materna ${ }^{30}$.

Podemos dizer que a proficiência em Matemática requer também a proficiência em língua materna, assim como nas demais disciplinas escolares, para um ensino-aprendizagem contextualizado, que explore nos estudantes as capacidades de

dividir, no dia a dia, pode se dar sem que as partes sejam iguais, ou seja, podemos dividir uma quantidade, na perspectiva cotidiano, em pares diferentes. (AZERÊDO; RÊGO, 2016, p. 159).

${ }^{29}$ Ao afirmar que "A compreensão de um texto é um processo que se caracteriza pela utilização de conhecimento prévio: o leitor utiliza na leitura o que ele já sabe, o conhecimento adquirido ao longo de sua vida. É mediante a interação de diversos níveis de conhecimento, como o conhecimento linguístico, o textual, o conhecimento de mundo, que o leitor consegue construir o sentido de texto. É porque o leitor utiliza justamente diversos níveis de conhecimento que interagem entre si, a leitura é considerada um processo interativo. Pode-se dizer com segurança que sem o engajamento do conhecimento prévio do leitor não haverá compreensão." (KLEIMAN, 2000, p. 13).

30 Por exemplo, leciono em uma turma (x) de quarenta estudantes (40), com a crise da Covid-19, ela foi reduzida (-) à metade (20), isto pode ser traduzido, simbolicamente, para: $X=40-20, \log$, $X=20$. Ademais, pode haver uma relação de proporcionalidade entre os níveis de conhecimento da língua materna e a resolução de problemas, quanto maior for esse nível de conhecimento, maior tenderá a ser a capacidade de formulação, interpretação, compreensão e resolução de problemas matemáticos. Isso demonstra o quanto é essencial aprender a linguagem matemática, que passa pela leitura, escrita, interpretação e compreensão, como habilidades fundamentais no desenvolvimento cognitivo e da aprendizagem. 
leitura, escrita, análise, interpretação e compreensão, para que possam transpor tanto a linguagem materna para a linguagem matemática e vice-versa quanto os enunciados matemáticos para cálculos e equações e, assim, possam resolvê-los.

$\mathrm{Na}$ categoria Conhecimento das Regras Gramaticais, se considerarmos o depoimento que compõe a categoria, por exemplo, seria muito coerente discutir a necessidade de aprender e ensinar recursos linguísticos para assegurar a coesão textual que as regras gramaticais em uma perspectiva normativa. No entanto, na percepção da participante, a aprendizagem da língua materna é

\begin{abstract}
“[...] de extrema importância, pois pra gente elaborar uma atividade, essas atividades têm que estar, ah, com as devidas concordâncias, até mesmo porque, se não tiver, nosso aluno não vai entender o que está sendo pedido. E questão de pontuação, vírgula, tudo isso, para a melhor compreensão do aluno." (P3:)
\end{abstract}

De fato, esse conhecimento é fundamental para a compreensão das estruturas gramaticais; o uso correto e adequado da língua; expressão compreensível e redação de textos inteligíveis, que cumpram seu propósito comunicativo. A importância de aprender as regras gramaticais para escrever aumenta cada vez mais na rotina profissional de todos os cidadãos. Nesse contexto, a função da normatização gramatical $^{31}$ é ampliar a capacidade do estudante de usar a língua materna com o propósito de desenvolver a sua competência comunicativa, por meio de atividades com textos utilizados em diferentes situações de interação. Não se poderia restringir à gramática o ensino-aprendizagem da língua e o ensino da gramática não poderia ser reduzido às regras. Pois, é necessário despertar para uma visão ampliada de que "ensinar gramática é ensinar a língua em todas as suas variedades de uso, e ensinar regras é ensinar o domínio do uso" (POSSENTI, 1996, p. 86). Assim, é necessário que os falantes da língua materna tenham o conhecimento da riqueza dos meios expressivos disponíveis para se comunicarem e; reconheçam a necessidade de se apropriarem de saberes essenciais para melhorarem seu discurso e sua capacidade de leitura, escrita, interpretação e compreensão, tanto na Escola e Universidade (formação docente) quanto na sociedade. Em outras palavras, podemos dizer que:

\footnotetext{
31 Recordemos, a título histórico, que nos Parâmetros Curriculares Nacionais (PCN) de Língua Portuguesa consta que: "O trabalho com a normatização ortográfica deve estar contextualizado, basicamente, em situações em que os alunos tenham razões para escrever corretamente, em que a legibilidade seja fundamental porque existem leitores de fato para a escrita que produzem. Deve estar voltado para o desenvolvimento de uma atitude crítica em relação à própria escrita, ou seja, de preocupação com a adequação e correção dos textos. No entanto, diferentemente de outros aspectos da notação escrita - como a pontuação -, as restrições da norma ortográfica estão definidas basicamente no nível da palavra. Isso faz com que o ensino da ortografia possa desenvolver-se por meio tanto de atividades que tenham o texto como fonte de reflexão como de atividades que tenham palavras não necessariamente vinculadas a um texto específico." (BRASIL, 1997a, p. 58). Embora os PCN não estejam mais em vigência no sistema educacional brasileiro, com advento de novo currículo, o descrito na citação, não perdeu seu valor intelectual.
} 
[...] ensinar Português: dar aos alunos [ex.: licenciandos em matemática] condições para que dominem a língua escrita, não só como um conjunto de leis que regem a correta grafia das palavras e um conjunto de regras sintáticas que orientam a construção de frases, mas também com um complexo histórico-cultural que vem produzindo interpretações de textos reconhecidos como especialmente significativos para a constituição da história cultural expressa na língua escrita (NEVES et al., 2007, p. 145).

É uma perspectiva defensável, pois ao aprender as regras corretas, o estudante não encontrará tantas dificuldades para a leitura, escrita, interpretação e compreensão dos textos e não só. A ortografia tem a função de preservar a inteligibilidade dos textos, diante das variações regionais, sociais e históricas de pronúncias das palavras, por exemplo. É preciso ensinar ortografia para solucionar os problemas que surgirão no processo de aquisição da leitura e escrita.

Portanto, para o campo da formação e atuação docente, a aprendizagem do padrão linguístico permitirá ao professor de matemática a organização coerente das proposições dos enunciados matemáticos e a organização lógica da prática didática. Pois, na formulação de exercícios ou instrumentos de avaliação, a incoerência ortográfica, sintática ou de concordância verbal, nominal ou verbo-nominal no texto de um problema matemático não permite ao estudante a compreensão do que é solicitado resolver. Assim, o conhecimento da gramática $^{32}$ se aplica ao ensino e compreensão de problemas matemáticos.

Na Flexibilidade no Discurso, a aprendizagem do padrão da língua materna proporciona um vasto léxico, que dá as possibilidades de construir um discurso ${ }^{33}$ flexível e adaptável às mais distintas situações comunicativas. A língua é considerada um sistema vivo, que muda constantemente e acompanha um povo e suas transformações ao longo dos tempos, nomeia coisas existentes e apresenta estruturas

\footnotetext{
32 Por exemplo: conhecimentos de sintaxe; semântica; ortografia; estrutura morfológica; concordância verbal, nominal e verbo-nominal, entre outros. Tradicionalmente, o ensino da Língua Portuguesa é de responsabilidade de profissionais formados em letras/linguística, são eles que lecionam, por exemplo, as disciplinas da área nas licenciaturas. Ocorre também que nem todos os cursos têm oportunizado a aprendizagem avançada da língua materna, o que gera problemas ou déficits de desenvolvimento das habilidades linguísticas e profissionais. No entanto, todos os profissionais devem dominar a língua materna, pois, é por meio dela que todas as atividades são expressas.

${ }^{33}$ Ao mencionarmos discurso, nos referimos enquanto fala, enunciação, que pode ser oral ou escrita. 0 professor de matemática produz um discurso ao ensinar a matemática que incluem números e palavras.
} 
linguísticas mutáveis, mudando e reinventando-se com as pessoas. Essa flexibilidade discursiva exige do falante capacidades necessárias para a produção de enunciados consistentes e coerentes, que lhe confere o desenvolvimento da "[...] competência básica para produzir um enunciado: o falante deve conhecer a gramática (sistemas fonológico, morfológico e sintático) e o léxico de uma língua para nela produzir enunciados gramaticais e aceitáveis; [...]." (FIORIN, 2002, p. 32).

Assim, aprendizagem e o conhecimento da Língua é uma condição necessária ao docente, de forma ampla, para melhorar o seu discurso e torná-lo flexível. A flexibilidade discursiva é a expressão da plasticidade intelectual comunicativa desenvolvida ao longo da aprendizagem avançada da língua materna. Cada cidadão pode construir um processo comunicativo baseado na flexibilidade de suas falas, dispondo de inúmeras estruturas linguísticas que lhe possibilitarão escolher a mais adequada a cada situação comunicativa. Assim, o professor de Matemática com a plasticidade intelectual comunicativa desenvolvida ao longo da aprendizagem da língua materna, terá a opção de se organizar linguisticamente para proporcionar uma situação de aprendizagem adaptada à realidade dos estudantes e, portanto, efetiva ${ }^{34}$.

Na Facilidade na Escrita, a escrita é uma habilidade ensinada desde os primeiros anos escolares, em que os estudantes têm contato com a alfabetização, cuja complexidade evolui conforme a progressão escolar, pois,

Para aprender a escrever, é necessário ter acesso à diversidade de textos escritos, testemunhar a utilização que se faz da escrita em diferentes circunstâncias, defrontar-se com as reais questões que a escrita coloca a quem se propõe produzi-la, arriscar-se a fazer como consegue e receber ajuda de quem já sabe escrever. Sendo assim, o tratamento que se dá à escrita na escola não pode inibir os alunos ou afastá-los do que se pretende; ao contrário, é preciso aproximá-los, principalmente quando são iniciados 'oficialmente' no mundo da escrita por meio da alfabetização. Afinal, esse é o início de um

${ }^{34}$ Ora, o ensino da Língua Portuguesa precisa estar relacionado ao estudo da língua em suas reais condições de uso, com a finalidade de proporcionar aos estudantes de todos os níveis escolares o conhecimento e o domínio das diferentes formas de comunicação - abrangendo desta forma, além da norma culta e sua gramática, as habilidades linguísticas essenciais e básicas. E, que permitem agir socialmente no uso da língua e ser capazes de se adaptar às situações vivenciadas. Isto evita situações em que os estudantes apresentem dificuldades em compreender um problema matemático proposto, devido ao entendimento inadequado das palavras utilizadas no enunciado e ao não reconhecimento das relações matemáticas associadas a uma dada situação. Os estudantes precisam ter familiaridade com o acervo linguístico utilizado, além de dominarem os conceitos necessários para entender a situação-problema apresentada. 
caminho que deverão trilhar para se transformarem em cidadãos da cultura escrita. (BRASIL, 1997a, p. 48).

A melhoria da habilidade da escrita é possível quando em consonância com a evolução da leitura, trata-se de processos simultâneos e indissociáveis. Essas duas habilidades caminham juntas para a promoção da proficiência dos estudantes. Ao ensinar o estudante a escrever a matemática, o professor está apresentando a ele os contextos de diálogo com a língua escrita. Oportunizando o desenvolvimento da escrita significativa, com o intuito de que o estudante tenha a oportunidade de exercer essa habilidade como uma prática social. Isto porque

O mais importante contexto de diálogo em que o texto do aluno precisa ser inserido é o contexto bem próximo da sala de aula: sua leitura pública e a consequente discussão pelos colegas e pelo professor tem a finalidade de levar o autor a reescrever o texto para qualificar sua participação nesses diálogos todos. (NEVES et. al., 2007, p. 155).

Assim, a aprendizagem do padrão linguístico deve proporcionar ao licenciando em Matemática as habilidades de ler e escrever criativa e criticamente a matemática, por meio da língua materna. Desenvolvidas tais habilidades no docente espera-se que as promovam nos estudantes na sua prática profissional. Para tanto, é necessário que todos os professores, das mais diversas áreas de ensino, estejam engajados nesse processo de desenvolvimento de habilidades linguísticas, uma vez que, em todas as disciplinas se utiliza a escrita, leitura, interpretação e compreensão em língua materna. Pois, "ler e escrever são tarefas da escola, questões para todas as áreas, uma vez que são habilidades indispensáveis para a formação de um estudante, que é responsabilidade da escola" (NEVES et al. 2007, p. 17).

Na Habilidade de Comunicação, o domínio da língua materna traz amplos benefícios para os cidadãos. No ensino da Matemática, isso fica evidente, conforme temos argumentado. Uma interpretação de textos coerente significa um caminho eficaz para a resolução de questões matemáticas. Contudo, em diversas situações, verifica-se a predominância do silêncio, no sentido de ausência de comunicação - isso é comum também em Matemática. Os exaustivos cálculos mecânicos, a linguagem hermética e abstrata usada para explicar os conceitos matemáticos e os hábitos tradicionais de ensino que não permitem explorar tanto os contextos quanto a 
comunicação entre professor e estudantes, tornam a comunicação quase inexistente e se existe é seca e estéril. Pode-se dizer que a eficácia da comunicação é assinalada pela expressão pessoal construída a partir das regras linguísticas estabelecidas, além do contexto individual vivenciado. Isso se aplica tanto à expressão escrita quanto à oral. A comunicação oral em sala de aula é um recurso que deve ser utilizado para favorecer a aprendizagem da Matemática, isto porque

Estimulando esse falar, estamos permitindo que os alunos modifiquem conhecimentos prévios e construam novos significados para as ideias matemáticas. Dessa forma, simultaneamente, os alunos refletem sobre os conceitos e os procedimentos envolvidos na atividade proposta, apropriam-se deles, revisam o que não entenderam, ampliam o que compreenderam, e, ainda, explicitam suas dúvidas e dificuldades. (SMOLE; DINIZ, 2001, p. 17).

Assim, entendemos que a comunicação oral conduz à percepção das diferenças existentes nos discursos, auxilia a convivência entre os estudantes, favorece os hábitos de escuta e da aprendizagem coletiva. A habilidade de comunicação é considerada a fonte inicial para a aprendizagem da Matemática, uma vez que, para aprendê-la e entender conceitos e informações veiculadas, é necessário haver comunicação significativa entre os estudantes e professores envolvidos no processo de escolarização, em todos os níveis do sistema educacional.

\section{Considerações Finais}

A partir dos dados podemos afirmar que os professores participantes da pesquisa tiveram, na sua maioria, uma licenciatura em Matemática que não lhes permitiu aprofundar-se em estudos de desenvolvimento das habilidades linguísticas e sua capacidade de intelectual e profissional. Os cursos de licenciatura têm dado ênfase formativa aos componentes curriculares específicos de matemática, o que foi percebido nas respostas dos participantes, e, os poucos que tiveram acesso a um componente curricular de Produção de Texto e Leitura, alegaram tempo insuficiente dedicado aos estudos. Por outro lado, a análise curricular também demonstrou que os conteúdos são insuficientes para que pudessem permitir o desenvolvimento das habilidades linguísticas de planejamento, elaboração, exploração, anélise, leitura, escrita, interpretação, compreensão, absorção, explicação e demonstração dos enunciados dos problemas matemáticos, formulação e resolução dos exercícios, 
associação e transposição de conceitos matemáticos, apresentação de conteúdo complexo, flexibilização da linguagem matemática, contextualização e adequação ao nível estudantil, o que gera déficit na capacidade de criação de instrumentos próprios de avaliação, por exemplo.

De acordo com análise das percepções dos entrevistados, podemos responder ao problema de pesquisa - (quais as contribuições do conhecimento do padrão linguístico (língua portuguesa) no ensino-aprendizagem da Matemática, a partir das percepções dos professores de matemática?) - que nas suas percepções foram constatadas as contribuições do conhecimento da Língua Portuguesa para o ensino e a aprendizagem da Matemática, sintetizadas em seis categorias, demonstrando-se que tal conhecimento contribui para: 1) explicação e expressão acessível dos enunciados matemáticos; 2) facilidade na compreensão e interpretação; 3) conhecimento das regras gramaticais; 4) flexibilidade no discurso; 5) facilidade na escrita e, 6) fluência na habilidade de comunicação. Estas categorias indicam também necessidades formativas em Língua Portuguesa, já que representam lacunas de formação e desempenho profissional docente.

Pois, trata-se de um conjunto de saberes profissionais, comumente, não valorizado na formação dos professores de Matemática. Fazendo-lhes crer que apenas os conhecimentos restritos de cálculos, números, equações, álgebra e análise geométrica, por exemplo, são necessários e suficientes para o desenvolvimento das capacidades e habilidades profissionais docentes, olvidando-se das habilidades linguísticas e dos conhecimentos da estrutura da língua padrão, para promoção da aprendizagem e solução de problemas ou situações-problemas matemáticas. Tais habilidades ampliam o conhecimento específico, transcendendo-o, promovendo práticas didáticas significativas e proficientes.

Por fim, é necessário rever o espaço que o ensino-aprendizagem do padrão da língua materna ocupa na formação de professores de matemática, para evitar um arranjo produtivo de défices formativos que se traduzem em obstáculos de aprendizagem e prática profissionais: uma formação em série de alfabetizados não letrados! Cabe, portanto, à escola e universidade viabilizarem o acesso ao universo das habilidades linguísticas básica e avançadas e às diversas formas e contextos de transposição discursiva em todas as disciplinas escolares ou acadêmicas. 


\section{Referências}

AZERÊDO, Maria Alves de; RÊGO, Rogéria Gaudêncio do. Linguagem e Matemática: a importância dos diferentes registros semióticos. Revista Temas em Educação, João Pessoa, v. 15, Número Especial, p. 157-172, 2016.

BARDIN, L. Análise de Conteúdo. São Paulo: Edições 70, 2016.

BITTENCOURT, J. F. A importância da leitura e interpretação do texto do problema matemático. Universidade Estadual de Ponta Grossa, 2008. Disponível em: http://www.shorturl.at/puS49. Acesso em: 18 jul. 2018.

BRASIL. Ministério da Educação. Secretaria de Educação Fundamental. Parâmetros Curriculares Nacionais: Língua Portuguesa. Brasília: MEC/SEF, 1997a.

CAMPOS, K.; BARCELOS, J. Do português para o "matematiquês": uma proposta interdisciplinar. Anais do Encontro Mineiro de Educação Matemática - EMEM. 2015. Disponível em: <https://bit.ly/2Ljv4sy>. Acesso em: 28 jan. 2019.

COURA, F. C. F. Matemática e Língua Materna: Propostas para uma interação positiva. X Ebrapem - Encontro Brasileiro de Estudantes de Pós-Graduação em Educação Matemática. Anais [...]. Universidade Federal de Minas Gerais, Belo Horizonte, 2006. Disponível em: <www.fae.ufmg.br/ebrapem/comunicações>. Acesso em: 02 ago. 2018.

FIORIN, J. L. As astúcias da enunciação. 2ạ ed. São Paulo: Ática, 1996.

FREITAS, T. dos S. Língua materna e linguagem matemática: influências na resolução de problemas matemáticos. 2015. Dissertação (Mestrado Profissional em Ensino de Ciências e Matemática) - Universidade Estadual da Paraíba, Campina Grande, 2015. Disponível em: <https://bit.ly/35PcL6w>. Acesso em: 20 ago. 2019.

IMBERNÓN, F. Formação docente e profissional: formar-se para a mudança e a incerteza. São Paulo: Cortez, 2011.

KLEIMAN, Â. B. Texto e leitor: aspectos cognitivos da leitura. 7ạ ed., Campinas: Pontes, 2000.

MARQUES, R. M. A. Matemática e Língua Portuguesa: laços para o sucesso? 2008.

Dissertação (Mestrado em Educação - Didática da Matemática) - Faculdade de Ciências, Departamento de Educação, Universidade de Lisboa, Lisboa, 2008. Disponível em: <https://bit.ly/3a2XQZS>. Acesso em: 20 ago. 2019.

NACARATO, A. M.; MENGALI, B. L. S.; PASSOS, C. L. B. A Matemática nos anos iniciais do Ensino Fundamental: tecendo fios do ensinar e do aprender. 2. ed. Belo Horizonte: Autêntica, 2017.

NEVES, I. C. B. et al. Ler e escrever: compromisso de todas as áreas. 8. ed. Porto Alegre: Editora da URFGS, 2007. 
PINHEIRO, T. C. da S.; ALVES, F. J. da C. A presença da interpretação de textos no ensino de matemática: as dificuldades enfrentadas pelos professores. Didática e Prática de Ensino na relação com a Formação de Professores. EdUECE - Livro 2, 2014. Disponível em:

<https://bit.ly/30bx900>. Acesso em: 28 jul. 2018.

POSSENTI, S. Por que (não) ensinar gramática na escola. Campinas, SP: Mercado de Letras, 1996.

HERNÁNDEZ SAMPIERI, R. Metodologia de Pesquisa. 5. ed. Porto Alegre: Penso, 2013.

SILVA, C. I. A. A Língua Portuguesa numa Perspectiva Transversal Discurso Pedagógico na Aula de Matemática. 2013. Tese (Doutoramento em Letras) -Universidade da Beira Interior, Covilhã, Portugal, 2013. Disponível em:

<https://ubibliorum.ubi.pt/bitstream/10400.6/1841/1/Capa.pdf>. Acesso em: 28 jan. 2019.

SILVEIRA, M. R. A. da; RIPARDO, R. Matemática versus Língua Portuguesa: o ângulo agudo de uma relação ímpar. Revista Margens Interdisciplinar, Universidade Federal do Pará, Campus Universitário de Abaetetuba, Ed. Campus de Abaetetuba, Pará, 2016.

SMOLE, K. S; DINIZ, M. I. Ler, escrever e resolver problemas: habilidades básicas para aprender matemática. Porto Alegre: Artmed, 2001.

UNIVERSIDADE DO ESTADO DE MATO GROSSO-UNEMAT. Projeto Pedagógico do Curso de Matemática. Campus de Barra do Bugres, UNEMAT, 2009. Disponível em:

http://bbg.unemat.br/ws-core-bbg/cursos/download/curso07-11-

2018_20_57PPCMatemticapdf.pdf. Acesso em: 28 jan. 2019.

UNIVERSIDADE DO ESTADO DE MATO GROSSO-UNEMAT. Projeto Pedagógico do Curso de Matemática. Campus de Cáceres, UNEMAT, 2018. Disponível em:

http://caceres.unemat.br/portal/matematica/wpcontent/uploads/sites/21/2018/08/PPC-matem\%C3\%A1tica-implanta\%C3\%A7\%C3\%A3o2018-1-encaminhado-colegiado-05-12.pdf. Acesso em: 02 jan. 2019.

UNIVERSIDADE DO ESTADO DE MATO GROSSO-UNEMAT. Projeto Pedagógico do Curso de Matemática. Campus de Sinop, UNEMAT, 2013. Disponível em: <https://bit.ly/38bKTea>. Acesso em: 02 jan. 2019.

Recebido em: 16 abril 2021 Aceite em: 15 outubro 2021 